\title{
Artistas do nosso trabalho no cuidado de feridas
}

\author{
Artistas de nuestro quehacer en el cuidado de las heridas
}

\author{
Artists of our wound care nursing tasks
}

\author{
Mery Luz Valderrama-Sanabria* \\ Luz Marina Clavijo-Alvarez ${ }^{* *}$
}

\begin{abstract}
Autor de correspondencia
* Enfermera. Magister en Enfermería, Especialista en Cuidado Crítico Pediátrico. Doctoranda en Educación. Docente Universidad de los Llanos, Grupo de Investigación de Cuidado. Correo: mvalderrama@unillanos.edu.co. Orcid: https://orcid. org/0000-0003-1618-6009. Villavicencio, Colombia.

${ }^{* * *}$ Enfermera. Especialista en Auditoría en servicios de Salud. Magíster en Educación. Docente Universidad de los Llanos, Grupo de Investigación GESI. Correo:1clavijo@unillanos.edu.co Orcid: https:/ orcid.org/0000-0002-8515-7116. Villavicencio, Colombia.
\end{abstract}

Este es un artículo bajo la licencia CC BY

(https://creativecommons.org/ licenses/by/4.0/) @) (;)

\section{Resumo}

Introdução: Os padrões de conhecimento fazem possível a análise de percepções do cuidado e permitem estudar o rol da disciplina. Constroem-se e nutrem a experiência única do cuidado de cada pessoa e fundamentam-se nas formas da prática da enfermagem, fornecendo elementos fundamentais no ensino. O tratamento de lesões de pele é um ato de cuidado, que permite identificar os padrões do conhecimento. Objetivo: Analisar a experiência de acadêmicos de enfermagem enquadrados nos padrões do conhecimento aplicados ao cuidado da pessoa com lesões de pele. Materiais e métodos: Pesquisa qualitativa de caráter fenomenológico interpretativo. Exploraram-se e analisaram-se as narrativas de acadêmicos de enfermagem que vivenciaram o cuidado de pessoas com ferimentos através dos padrões de conhecimento. A amostra foi constituída por seis alunos de enfermagem. A amostragem obteve-se por pertinência, adequação, conveniência, oportunidade e disponibilidade. Utilizaram-se entrevistas a profundidade, observação e anotações de campo Resultados: O trabalho dos alunos esteve baseada na prevenção e tratamento das lesões de pele, fornecendo um cuidado integral. Durante o processo identificaram-se os padrões do conhecimento empírico, pessoal, estético, emancipatório, ético e sociopolítico. Conclusões: Os futuros profissionais da enfermagem compreenderam a importância de prestar atenção através desses padrões, entendendo as necessidades de cada pessoa e incentivando o autocuidado. É importante fortalecer a pesquisa formativa, a fim de gerar espaços de discussão e construção do conhecimento.

Palavras-chave: Ferimentos e lesões, conhecimento, educação em enfermagem, alunos de enfermagem.

\section{Resumen}

Introducción: Los patrones de conocimiento, hacen posible el análisis de percepciones de cuidado y permiten estudiar el quehacer de la disciplina. Se construyen y alimentan en la experiencia única de cuidado de cada persona y se fundamentan en las formas de ejercicio de la enfermería, aportando elementos fundamentales en la enseñanza. El manejo de las heridas es un acto de cuidado, que permite vislumbrar los patrones de conocimiento. El objetivo de este estudio fue analizar la experiencia 
de los estudiantes de enfermería enmarcada dentro de los patrones de conocimiento aplicados al cuidado de la persona con heridas. Materiales y método: Investigación cualitativa, de carácter fenomenológico interpretativo. Se exploraron y analizaron narrativas de estudiantes de enfermería que vivenciaron el cuidado de la persona con heridas a través de los patrones de conocimiento. La muestra estuvo constituida por seis estudiantes de enfermería. El tipo de muestreo se realizó por pertinencia, adecuación, conveniencia, oportunidad y disponibilidad. Se utilizaron entrevistas a profundidad, observación y notas de campo. Resultados: La labor del estudiante estuvo enmarcada en la prevención y tratamiento de las heridas, brindando cuidado integral. Durante el proceso se identificaron los patrones de conocimiento empírico, personal, estético, emancipatorio, ético y sociopolítico. Conclusiones: Los futuros profesionales de la enfermería comprendieron la importancia de brindar atención a través de estos patrones, entendiendo las necesidades de cada persona y fomentando el autocuidado. Es importante fortalecer la investigación formativa, con el fin de generar espacios de discusión y construcción del conocimiento.

Palabras clave: Heridas y lesiones, conocimiento, educación en enfermería, estudiantes de enfermería.

\begin{abstract}
Introduction: Knowledge patterns make possible the analysis of perception of nursing care and also allow the study of the tasks of the discipline. These are built and fueled by the unique care experience of each person and are based on the types of nursing care, contributing fundamental education elements. Wound care nursing gives a glimpse of knowledge patterns. The objective of this study was analyzing the experience of nursing students, framed within the knowledge patterns applied to the care of people with wounds. Materials y Method: Qualitative research, of interpretative phenomenological character. Narratives were explored and analyzed from nursing students that experienced providing care to patients with wounds through knowledge patterns. The sample was made of six nursing students. The sampling was made by relevance, adequation, convenience, opportunity and availability. The instruments used were in-depth interviews, observation and field notes. Results: The objective of the student was focused on the prevention and treatment of wounds, providing comprehensive care. During the process patterns of empiric, personal, esthetic, emancipatory and sociopolitical knowledge were identified. Conclusions: Future nursing professionals understood the importance of providing care through these patterns, understanding the needs of each person and encouraging selfcare. It is important to empower formative research, with the end of generating spaces of discussion and construction of knowledge.
\end{abstract}

Keywords: Wounds and injuries, knowledge, nursing education, nursing students.

\section{Introdução}

Os padrões de conhecimento, fazem possível a análise das percepções do cuidado e permitem de maneira inovadora estudar a enfermagem (1-3); igualmente, dão significado ao tipo de conhecimento aplicado à disciplina; constroem e alimentam à experiência única de cada pessoa com seu sujeito de cuidado fundamentando as formas do exercício da enfermagem, o acumulo dos conhecimentos empíricos, éticos, estéticos e pessoais, gerando elementos fundamentais no ensino de enfermagem. Além disso, servem para compreender a experiência que vive o outro, respeitando a sua autonomia orientando a prática do cuidado (4-6). Estes saberes podem ser utilizados nos diferentes contextos do desempenho profissional, cada padrão é essencial e depende dos demais para integrar o tudo na prática profissional. Porém, aprender os diferentes padrões do conhecimento pode ser ocasionalmente complexo, dado que depende não só das estratégias pedagógicas, também atuam a motivação e o interesse transmitido aos alunos da enfermagem; neste sentido, é mais simples aprender do conhecimento empírico que do ético, o estético e especialmente, o pessoal; sendo isso hoje em dia o desafio da compreensão e aplicação através da expressão artística, para acordar a sensibilidade necessária no profissional da enfermagem (7).

Inicialmente, Carper identificou quatro padrões do conhecimento disciplinar: o empírico-científico, ético, pessoal e estético; posteriormente White acrescentou o padrão sociopolítico (8) e recentemente o padrão emancipador foi incorporado por Chinn \& Cramer (4). Estes padrões permitem afirmar que a 
ISSN-PRINT

1794-9831

E-ISSN 2322-7028

Vol. 16 No. 3

Sep - Dic 2019

Cúcuta, Colombia enfermagem não é só técnica, é uma disciplina que possui fundamentos que contribuem ao seu desenvolvimento (9).

O padrão de conhecimento empírico refere-se à ciência da enfermagem, permite gerar teoria e contém os diferentes paradigmas de pesquisa (9). Tem como objetivo desenvolver o conhecimento abstrato e as explicações teóricas através da observação e a repetição dos fenômenos determinando a efetividade na prática de enfermagem (6-10).

Enquanto o padrão do conhecimento estético é a expressão artística da disciplina, visível nas ações, atitudes e interações $(9,11)$. Esta arte é subjetiva, expressiva e concretiza-se no cuidado, e não pode ser reduzido à simples execução de técnicas. Relacionase com a prática profissional expressada na interação enfermeira-paciente, integrando a habilidade técnica e pessoal, utilizando o conhecimento e o raciocínio clínico. É a compreensão do significado numa expressão subjetiva, única e particular; sendo visível mediante as ações, comportamentos, atitudes condutas e interações do enfermeiro frente aos outros (12).

O padrão de conhecimento pessoal é o entendimento e o encontro de si mesmo que permite estabelecer uma relação de reciprocidade com o outro. Significa aproximar-se da pessoa respeitando-a como sujeito, aceitando a sua liberdade, promovendo a totalidade e integridade na relação pessoal, negando a manipulação e a impessoalidade (12). Wilches \& Wilches, mencionaram que este padrão é fundamental para o desenvolvimento dos demais, destacando a necessidade que o profissional se reconheça, e nesse autoconhecimento, logre reconhecer a diferença do outro. A relação terapêutica que se estabelece deve ser respeitosa, cálida e tendo presente a individualidade da dignidade humana (13-15).

No padrão do conhecimento ético conjugam-se os demais padrões, sua base é o "dever fazer, procurando sempre que as coisas resultem da melhor maneira, implementando os conhecimentos prévios e o sentido humano que faz parte da profissão. No que fazer do enfermeiro, enfrenta-se aos dilemas éticos para o que precisa ter um desempenho ótimo comprometido com o bem-estar do outro e a toma de decisões adequadas para as pessoas $(13,15)$. Este padrão fornece parâmetros para explorar os fenómenos axiológicos da enfermagem, os valores deontológicos do exercício profissional, tais como o respeito, a individualidade, a dignidade, o amor, entre outros, e inclui todas as ações voluntárias que estão sujeitas ao juízo do que está bem e o que está mal (14).

O padrão de conhecimento sociopolítico tem sido proposto por White como o contexto da enfermagem. Este padrão é essencial para entender os demais. Refere-se ao conhecimento transversal, gerando questionamentos na enfermagem pelo constante enfrentamento entre a realidade da pratica, a profissão e as políticas de saúde. Este conhecimento pode-se entender desde os aspectos do contexto sociopolítico das pessoas envolvidas no ato do cuidado, ou seja, o enfermeiro e o paciente, incluindo o conhecimento que a sociedade tem sobre o papel do enfermeiro, assim como o conhecimento que o enfermeiro tem sobre a sociedade e as políticas sociais e económicas de onde atua (12).

Finalmente, o padrão de conhecimento emancipatório tem sido proposto como a consciência de justiça e equidade na profíssão (9), enlaçando e contornando os quatro padrões iniciais, permitindo uma visão crítica sobre as atuações para o desenvolvimento do conhecimento. É a capacidade não só de reconhecer as injustiças sociais, também de examinar criticamente o fato de não serem reconhecidos no primeiro olhar pela sociedade. Está relacionado com a solução de problemas, o pensamento crítico, e a prática reflexiva onde a ação e a reflexão interatuem constantemente para dar forma ao que se faz e como se faz (16).

Deve-se frisar que nenhum padrão pode ser utilizado de forma isolada, porém devem estar interatuando de maneira interdependente. Partindo dessa perspectiva, o cuidado das lesões e ferimentos crônicos é um ato propicio para visualizar cada um desses padrões, convertendo-se num desafio para o enfermeiro, devido às diversas causas que os produzem, o aumento dos produtos disponíveis no mercado para o seu tratamento, assim como as práticas carentes de evidencia cientifica, razões pelas que a enfermeira deve decidir de realizar a intervenção que mais favoreça o paciente, partindo dos conhecimentos na fisiologia do processo de cicatrização junto da seleção dos materiais e produtos que contribuam à cicatrização $(17,18)$.

No que diz respeito ao cuidado de pessoas com ferimentos, devem ser abordados partindo de todas as suas dimensões, dado que o paciente está exposto a riscos microbiológicos e fisiológicos, mas também, 
a mudanças psicológicas e no desenvolvimento de suas funções sociais (19). Tem sido evidenciado que a formação dos profissionais de enfermagem nessa área não é a mais completa, porque tem se omitido o ensino de elementos indispensáveis, portanto, é fundamental fornecer conhecimentos claros sobre a pele e o cuidado de lesões, além disso, atualizar-se assistindo a congressos sobre o tema, à aplicação de guias de prática clínica e leitura de artigos científicos. Os senários de prática formativa têm uma grande influência na toma de decisões efetivas para o cuidado desse tipo de pessoas (20).

Partindo do exposto, deve-se frisar que a equipe de enfermagem é responsável pela assistência desde a sua internação até o egresso, além também do seguimento domiciliar, promovendo cuidados de qualidade encaminhados ao cumprimento do tratamento e redução das complicações. Do mesmo jeito, têm de proporcionar-lhe cuidados individualizados, humanizados e holísticos que procurem compreender o contexto fisiopatológico, psicológico, social e ambiental que está imerso $(21,22)$. Este estudo oferece contribuições à disciplina ao aplicar referentes epistemológicos na docência e na prática, fortalecendo o cuidado da pessoa com lesões de pele, igualmente, oferece padrões de conhecimento que servirão de guia à prática formativa e a toma de decisões baseadas na evidencia.

\section{Objetivos}

\section{Objetivo geral}

Analisar a experiência dos alunos da enfermagem respeito dos padrões de conhecimento aplicados à pessoa com ferimentos

\section{Objetivos específicos}

- Identificar no ato do cuidado das lesões de pele os padrões de conhecimento em enfermagem.

- Conhecer as condições que limitam ou favoreçam o cuidado de ferimentos através de padrões de conhecimento.

\section{Materiais e métodos}

Realizou-se uma pesquisa qualitativa de tipo fenomenológico interpretativo, onde exploraram-se e analisaram-se narrativas de acadêmicos de enfermagem do VII período, que vivenciaram o cuidado da pessoa com ferimentos através dos padrões de conhecimento, numa instituição de saúde de segundo nível de complexidade no segundo semestre de 2017. Considerou-se este tipo de estudo pelo seu interesse no estudo da experiência humana desde a perspectiva dos participantes. Elegeu-se a experiência da prática formativa dos alunos na línea de aprofundamento "cuidado ao paciente com ferimentos".

De acordo com Silva \& Trentini, a narrativa implica a expressão e obtenção de informação da experiência dos participantes, nesta ocasião foram o paciente, um parente e o aluno de enfermagem. Portanto, a análise das narrativas proporcionou significados, conflitos, resoluções e construções disciplinares. Além disso, foram utilizadas como método de análise e pesquisa fornecendo um conhecimento profundo do momento do cuidado à pessoa, permitindo identificar os fenómenos tal e como os viveu o aluno (23).

A amostra foi integrada por seis acadêmicos de enfermagem que ofereceram informação profunda e em detalhe sobre o assunto de interesse. Quatro deles corresponderam ao sexo feminino e dois ao masculino, com idades entre os 19 e 23 anos.

A amostragem foi por pertinência, adequação, conveniência, oportunidade e disponibilidade (24). A pertinência referiu-se à identificação dos seis participantes que aportaram maior e melhor informação aos objetivos de pesquisa, que assinaram previamente o termo de consentimento livre e esclarecido. A adequação constou em contar com dados suficientes e disponíveis que permitiram a descrição completa do fenómeno, hasta lograr a saturação da informação. A conveniência foi na seleção do lugar, selecionou-se um lugar que não gerara interferências. A oportunidade, logrou-se estando no momento justo e no lugar preciso para desenvolver a pesquisa. A disponibilidade deu o acesso livre e permanente ao lugar, situações ou eventos que demandou a pesquisa.

Realizou-se também a imersão ao campo, que constou da aproximação que realizaram as pesquisadoras ao contexto e aos participantes antes de serem abordados pelos alunos. Estabeleceu-se um diálogo aberto e espontâneo fazendo um primeiro exercício de entrevista, motivando aos participantes e gerando vínculos de confiança e intimidade para posteriormente coletar a informação sobre o fenômeno de estudo.

Para a coleta e análise da informação utilizou-se a en- $\overline{\text { E-ISSN 2322-7028 }}$

Vol. 16 No. 3

Sep - Dic 2019

Cúcuta, Colombia 
ISSN-PRINT

1794-9831

E-ISSN 2322-7028

Vol. 16 No. 3

Sep - Dic 2019

Cúcuta, Colombia trevista aberta e a profundidade, a observação participante e o diário de campo.

Segundo Sandoval (24), a entrevista a profundidade faz referência a várias sessões extensas e detalhadas com uma pessoa, partindo de uma pergunta central e a sua resposta vão gerando-se novas perguntas seguindo umas temáticas essenciais. As entrevistas foram gravadas e transcritas com assinatura previa do termo de consentimento livre e esclarecido. Por cada participante realizaram-se entre dois e três entrevistas com uma duração média de $40 \mathrm{~min}$. Foram executadas num ambiente agradável e de fácil acesso pelos participantes, respeitando a disponibilidade anímica e procurando evitar interrupções.

As observações dos participantes foram feitas nos sítios onde os alunos realizavam seu estágio prático de cuidado do paciente com ferimentos (instituição de saúde e domiciliar), determinando os elementos de interesse, para o qual desenvolveu-se uma guia que direcionou a atenção à percepção e experiência sobre o tema de pesquisa. Foram avaliados a interação dos alunos com os pacientes, o tipo de necessidades que priorizaram, a maneira como realizaram o ato de cuidado, entre outros.

O diário de campo registrou anotações que continham observações completas y detalhadas; através delas obtiveram-se dados que muitas vezes não foram logrados nas entrevistas. Considerou-se a linguagem não verbal que fazia referência a signos expressivos através de movimentos oculares, lágrimas que escorreram, a mimica, o acento, o timbre o tom da voz. O registro de estas variáveis foi feito de maneira discreta sem chamar a atenção dos participantes.

A análise iniciou-se a partir da transcrição textual das primeiras entrevistas e observações, centrado nos padrões de conhecimento no cuidado das lesões. Procedeu-se a denominar os conceitos e definir os padrões, empregando-se o método comparativo constante. Realizou-se a codificação em três níveis: o primeiro aberto, no qual realizou-se uma análise descritiva inicial dos códigos (as próprias palavras dos participantes) linha por linha, frase por frase, procurando palavras para estabelecer códigos e definir os padrões de conhecimento. Neste sentido, foram-se comparando os dados e cada entrevista com a anterior, sublinhando as palavras e frases relevantes que expressavam o fenômeno de estudo. A codificação axial identificouse com as relações entre os códigos e os temas centrais. Voltaram-se a unir os dados mediante a indução e a abstração para estabelecer a relação entre os códigos e os temas. Continuou-se comparando novos dados com os códigos emergentes, construindo relações iniciais entre os padrões. Na codificação seletiva, integraram-se os padrões de conhecimento com o fim de construir um esquema teórico maior (25).

Com o propósito de validar a pesquisa, consideraramse os aspectos de rigor durante o desenho e a implementação do estudo, garantindo a qualidade científica. Com a credibilidade, através das técnicas de recolecção da informação captou-se o significado completo e profundo das experiências, tendo a capacidade para comunicar a linguagem, pensamento, emoções e os pontos de vista dos participantes, ratificando a informação ministrada por eles. A confirmação dos dados demostrou-se mediante um processo objetivo apoiado na recolecção e nas continuas comprobações entre as pesquisadoras e os informantes, garantindo captar a realidade tal e como se percebia. A dependência e confiabilidade estiveram presentes desde o começo da pesquisa ao explicar cada etapa do estudo (25).

A codificação interna inclui a letra $\mathrm{E}$ para fazer referência à entrevista com o número da mesma $(1,2$ ou 3) e a letra $\mathrm{P}$ acompanhada de um número fazendo referência ao número do participante.

O desenvolvimento desta pesquisa considerou os lineamentos éticos da resolução 08430 do Ministério da Saúde da Colômbia e contou com a aprovação e auxilio da direção geral de pesquisa da Universidad de los Llanos No 02-2018.

\section{Resultados}

Os alunos participaram do cuidado à pessoa com ferimentos crônicos na pele. Na figura No1 identificamse os padrões de conhecimento que emergiram da análise de conteúdo. 


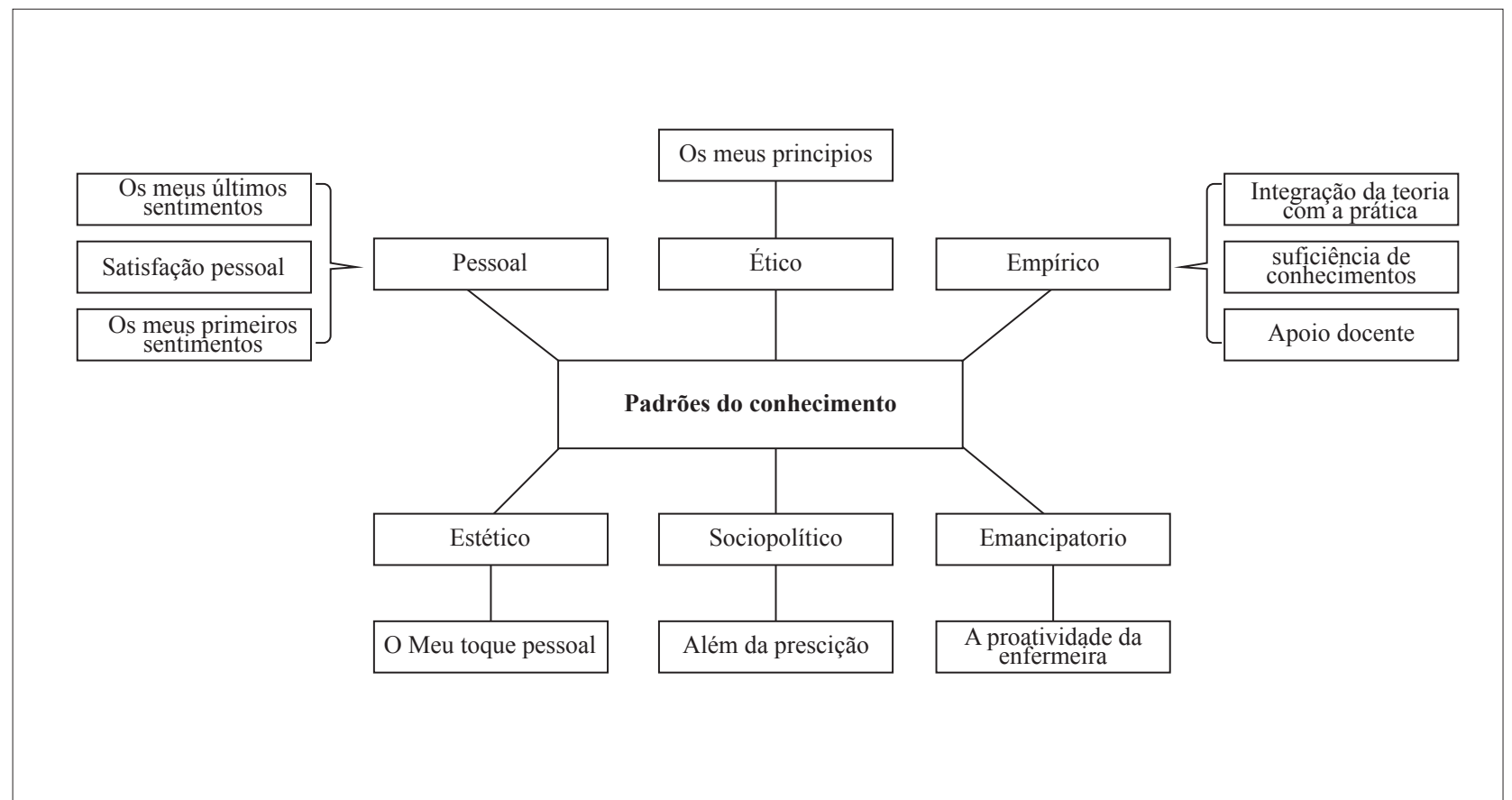

E-ISSN 2322-7028

Vol. 16 No. 3

Sep - Dic 2019

Cúcuta, Colombia

Figura $\mathbf{N}^{\circ}$ 1. Padrões do conhecimento

Fonte: Elaboração propria

\section{Padrão do conhecimento empírico}

A fundamentação deste padrão e a sua identificação no momento do cuidado viu-se refletido através do conhecimento disciplinar com a aplicação do processo de atenção de enfermagem, a integração da teoria com a prática e a utilidade das teorias e modelos de enfermagem.

Por outro lado, deve-se considerar o reconhecimento das condições da infraestrutura para fornecer o cuidado, a aplicação de protocolos de procedimentos em pessoas com lesões de pele, entender a condição física e emocional do paciente e compreende o estilo de vida do sujeito de cuidado, junto com o uso da tecnologia e o trabalho em equipe. Também fazem parte do padrão de conhecimento empírico as seguintes categorias:

\section{a. Integração da teoria com a prática}

$\mathrm{O}$ uso das teorias e os modelos de enfermagem é fundamental para compreender a natureza e disciplina de enfermagem, melhorando a qualidade do cuidado dos pacientes. Portanto, é pertinente que o conhecimento de enfermagem seja ensinado, aprendido e aplicado na prática clínica, porque a teoria sem prática é meramente ilusão e a prática sem teoria é como "roda solta". Só com a união de ambos os conceitos, continua o progresso da profissão.
"Claramente é necessário na prática e no desenvolvimento da ferida observava, entender como os efeitos bioquímicos e fisiológicos influem para o bem ou para o mal, pelo que tinha que ser cuidadoso, a teoria permite segurança ante qualquer circunstancia diferente dos processos comuns" [E2P1].

"Era indispensável ter os conhecimentos aprendidos durante às aulas teóricas para poder realizar o curativo da lesão da maneira correta e poder obter resultados satisfatórios" [E1P3].

\section{b. Suficiência de conhecimentos}

"Precisa-se uma série de instruções ou informação para atuar com segurança embora há umas bases construídas, contava com o conhecimento prévio para assumir e desenvolverme ao que diz respeito a essas circunstancias, mas não com total segurança" [E1P1].

"Ao momento de realizar o curativo sempre precisei lembrar toda a teoria que vimos durante o curso, já que era necessário saber tanto o processo fisiológico de cicatrização assim como o tratamento que precisava o paciente nesse momento para que lograra um processo satisfatório"[E2P2].

"Opaciente era um idoso quem tinha sequelas de 
ISSN-PRINT

1794-9831

E-ISSN 2322-7028

Vol. 16 No. 3

Sep - Dic 2019

Cúcuta, Colombia um AVC aparentemente isquêmico, com afasia e deterioro no nivel motor, não mostrava nenhuma manifestação no inicio do curativo, entretanto, ao passar os dias de visita estava alerta e lucido. Aprendemos a interpretar quando presentava dor pelos seus olhos e alguns movimentos dos braços, ações que anteriormente não fazia, mostrava-se de melhor aspecto com a sua expressão e isso é muito satisfatório" [E3P4].

"Embora que a pessoa não pudesse manifestarse verbalmente, com os seus movimentos tanto de seus olhos e as suas mãos nós fazia saber o grato que estava com a ajuda que estávamos the brindando" [E2P5].

\section{c. Apoio docente}

"Aplicando os conhecimentos prévios pois quando se tem temor e não há um professor que apoie estas práticas de maneira efetiva esqueçome de tudo o aprendido e poderia atuar de maneira errada, mas tudo consegui fazer bem com a ajuda das professoras e senti-me mais segura" [E2P6].

"A professora dava instruções claras, explícitas, com fundamentação teórica, segurança e confiança. Brindava a certeza sem arruinar ou destruir as nossas ideias a favor da melhora das lesões, pois mostrava aprecio e disposição todo o tempo para fornecer um cuidado de qualidade"[E2P4].

"A professora nós indicou desde como nós comunicar com o paciente e a sua família até como realizar o mais mínimo procedimento necessário para o curativo e sempre contamos com o seu apoio" [E1P4].

\section{Padrão do conhecimento pessoal}

Faz referência ao "Eu cuidador", demostrado pelo agrado pelo ato de cuidar, a capacidade de escuta atenta, a experiência intersubjetiva do aluno com a pessoa sujeito de cuidado, o uso de alternativas como a música, manter o sentido de humor com uma piada, além disso, satisfazer as necessidades espirituais como preservar a fé, rezar ou deixar ao lado os problemas pessoais. Surgiram as seguintes categorias:

\section{a. Os meus primeiros sentimentos}

"Ansiedade e temor, o primeiro que penso é não fazer mal ao paciente, mas logo lembro que tenho como ajuda-lo e fico cheio de confiança e segurança para poder fazê-lo. Quando fiz o curativo estava amedrontada pois não sabia ao que ia realmente me enfrentar, mas quando comecei senti que sabia, que não tinha a prática, mas pouco a pouco fui melhorando e com maior segurança realizava os procedimentos" [E1P1].

"Fiquei muito impressionada, não por ver a lesão, de ver o paciente, ao pensar como o corpo humano pode ser tão susceptivel ante uma doença, até deixa-lo num completo estado de dependência" [E2P2].

"No começo muita incerteza pelo estado em que estava o ferimento, ver o compromisso da pele e mais do que isso, o estado emocional do paciente pelo fato de ter essa lesão, que o impedia de fazer as suas atividades diárias. Tinha medo de pensar em não poder cumprir com o objetivo final que era a cicatrização da lesão" [E3P3].

\section{b. Meus últimos sentimentos}

"Cansaço, sei que pode parecer esquisito, mas me sentia esgotada, doiam-me as pernas, as costas e tinha dor de cabeça, mas a nível emocional sentia-me surpreendida do que eu podia fazer e de como a minha mente e as minhas mãos congeminavam para realizar o procedimento sem dificuldade, era como se já o houvesse realizado. O cuidado de enfermagem não ia somente enfocado aos dois ferimentos, também manter a higiene a nivel genital e que muitas vezes afetava o processo do curativo, já que uma das lesões era na região sacra" [E3P4].

"Felicidade e satisfação de saber que os ferimentos melhoraram e também o estado no geral do paciente, que não só devia olhar a lesão se não todo o paciente como melhorava, muito feliz dos avanços que se viram" [E3P2].

\section{c. Satisfação pessoal}

"Embora as jornadas acadêmicas e os deveres me mantinham ocupada e um pouco estressada, chegar à casa do paciente me produzia muita felicidade, pois a família tinha muita expectativa sobre nós como grupo de alunos e a professora. Realmente só o fato de ver as expressões do paciente e como verbalmente a sua esposa e filha mostravam agradecimento, é a melhor experiência que se pode ter. Às vezes me encontrava frustrada, pois o tempo todo não 
podia se obter facilmente os insumos para fazer os curativos, pelo que que era um obstáculo que tinha com o meu grupo dia a dia, quisesse poder ter feito mais",[E2P1].

"Orgulhosa de tudo que pudemos realizar porque o fizemos bem, motivada e disposta a servir ao paciente e a sua familia" [E2P5].

"Com algumas expressões comecei ver que apreciava nos ver, na forma de olhar-me o notei. Sempre lhe falava forte, com segurança, o cumprimentava e as vezes fazia algumas piadas para amenizar o momento do procedimento, mostrando mi interesse de não lhe fazer mal $e$ de explicar-lhe o que the iamos fazer, com expressões como "vamos nos virar" que com humor fazia para amenizar a situação" [E2P6].

"Alegria ao ver que tinha cumprido o objetivo proposto e observar que o seguimento que tinha sido feito tinha colhido seus frutos; finalmente o paciente teve tranquilidade ao ter cicatrizado a lesão e de novo podia fazer as suas atividades do dia a dia"'[E3P3].

"Inicialmente meu paciente era um homem que no primeiro olhar, se observava muito triste e impotente de ver-se dependente do seu filho para poder urinar ou fazer deposição, além disso manifestava que desde que tinha ficado maior a lesão tinha deixado de caminhar. Fui observando a evolução do ferimento, ia reduzindo o tamanho e logo pode voltar a fazer as suas atividades, como caminhar. Seu estado de animo passou de triste a estar feliz, voltou a sorrir e ter tranquilidade"[E3P4].

\section{Padrão do conhecimento estético}

Viu-se refletido na criatividade e estilo pessoal que deu cada aluno ao cuidado do seu paciente. Manifestou-se através dos significados que deram à expressão dos seus rostos, estar atento da pessoa mesmo que finalizado o plantão, envolver ao paciente e à sua família no cuidado, adiantar-se ao que precisa o paciente sem perguntar-lhe e procurar por melhorar a sua apresentação pessoal.

\section{a. O meu toque pessoal}

"Penso que foi a segurança com que desenvolvi e apliquei os meus conhecimentos, a empatia que pude ter com a família e o paciente, o sentido de humor e a criatividade para buscar soluções a partir da liderança que penso me caracteriza" [E2P1].

"Caracterizou-me pela minha agilidade $e$ cuidado ao realizar o curativo e a entrega para fornecer o melhor ao meu paciente" [E2P2].

"Quando eu realizava o curativo não só me baseava no método procedimental, também ia explicando o que fazia, o educávamos; então dava-lhe medidas de prevenção e também o seu componente espiritual e psicológico para que o paciente fosse mais positivo, já que estar com depressão era muito dificil, continuar intentando-o e cuidando-se com os demais aspectos como a alimentação que ele não queria se alimentar, mas logo depois sim quis fortalecer o seu autocuidado"[E2P3].

"Penso que o que me caracteriza é o amor pelo que eu faço, a dedicação que eu ponho para o cuidado que brindo, a perseverança no meu trabalho; esses foram os aspectos mais importantes que me levaram a cumprir o objetivo que me propus no começo" [E1P4].

"No primeiro encontro com o paciente e a sua familia, encontraram em mim uma pessoa com capacidade para escutar os seus sentimentos, temores e preocupações. $O$ meu paciente manifestou-me que estava cansado da sua vida, da sua doença, não tinha esperanças, sentia que era uma carga para a sua mulher, ela se via cansada, ela diz-me que tinha desejos de sair correndo e deixar de lutar, que ninguém a compreendia ou ajudava" [E2P5].

\section{Padrão do conhecimento emancipatório}

Foi identificado nos alunos através da autonomia demostrada embora tivessem dificuldades ao fornecer cuidados de qualidade e os câmbios que lograram propor para melhorar a indolência ante a injustiça e a desigualdades que apresentam-se com vantagens para uns e desvantagens para outros.

\section{a. A proatividade de enfermagem}

"Houve situações que iam além de demostrar os nossos conhecimentos, sempre fazíamos uso racional de cada curativo e tecnologia de alto custo, mas as vezes não contávamos com todos os materiais, isso doía demais"'[E3P3].
E-ISSN 2322-7028

Vol. 16 No. 3

Sep - Dic 2019

Cúcuta, Colombia 
ISSN-PRINT

1794-9831

E-ISSN 2322-7028

Vol. 16 No. 3

Sep - Dic 2019

Cúcuta, Colombia
"Sempre quis fornecer-lhe o melhor curativo ao meu paciente, fui proativa porque as vezes os materiais eram escassos, muitas vezes pedimos a contribuição das mesmas professoras e tínhamos que coletar dinheiro para fazer a compra dos insumos necessários'"[E2P4].

"Nas situações difíceis, procuramos a contribuição de laboratórios e marcas, embora foi pouca, serviu-nos para cobrir os recursos durante duas semanas" [E2P5].

"É triste ver a luta dos familiares perante os planos de saúde para que lhes deram os curativos e insumos necessários "[E2P6].

\section{Padrão do conhecimento ético}

Este padrão evidenciou-se através da aplicação dos princípios e valores éticos, assim como o compromisso e disponibilidade com o paciente. $\mathrm{O}$ aluno teve presentes os fatores que poderiam atentar contra o seu pudor e comunicaram sempre a verdade ao paciente e à sua família.

\section{a. Os meus princípios}

"Tive presente a autonomia onde eu consegui discernir e decidir qual era o processo da lesão, os métodos, os materiais e o procedimento para o curativo e também a beneficência que era o nosso objetivo, que o paciente se beneficiara cento por cento e obter uma melhor qualidade de vida, que não somente fosse o curativo do ferimento, também se sentisse com paz e tranquilidade total" [E2P1].

"Os princípios éticos para mim, os mais importantes no curativo com o meu paciente foram a beneficência e não maleficência, porque sempre procuramos que com todo o processo ele notasse a mudança e se sentisse bem, a gosto, que se desse conta que podia melhorar, curar-se e estar bem de saúde, começar a fazer atividades que tinha deixado de fazer pelo ferimento"[E2P2].

"No começo o paciente sentia um pouco de vergonha, pelo ferimento na região sacra, com muito respeito e pedindo licença, tiravamos as prendas íntimas, e com o passo do tempo fomos lhe gerando confiança e ele foi se adaptando, agradeceu-nos por cuidar-lhe" [E3P3].

"Os princípios que baseei-me foram a justiça e a autonomia, porque tinha os conhecimentos $e$ critérios para a abordagem da lesão"[E3P4].

\section{Padrão do conhecimento sociopolítico}

Viu-se refletido através da atenção da equipe multidisciplinar, a participação, a liderança, a toma de decisões e serem agentes de mudanças sociais.

\section{a. Além da prescrição}

"No começo a esposa mostrava-se apática pois tinha-se enfrentado a pessoal indolente que tinham permitido que os ferimentos pioraram, pelo que estava decepcionada de qualquer profissional da saúde e conhecemos a sua historia depois de ganhar a sua confiança. Aos poucos foi abrindo as portas da sua casa, oferecia -nos suco e bolachas que cabem menciona-las, pelo fato de ser um gesto de gratidão conosco, o que motivou a minha paixão pelo dever" [E2P4].

"Antigamente a esposa lhe fazia os curativos pela angustia de ver o seu marido nesse estado e era grandioso o que fazia, tinha os tecidos prontos para trabalhar nos curativos diários e o aloe vera que lhe punha. Sempre esteve disposta a oferecermos os materiais que dava o convenio de saúde e estava atenta a maior parte do tempo, fazendo perguntas sobre as condições e o progresso das lesões" [E1P5].

"Nós como grupo decidimos continuar os curativos embora tivéssemos acabado o nosso periodo acadêmico sob a supervisão da professora, entretanto numa ocasião que não se encontrava e não conseguimos nos comunicar com ela nós enfrentamos um dilema, entretanto, fizemos o procedimento baseados ao nosso conhecimento sem afetar o paciente"'[E3P6].

"Não só é o fato de realizar o curativo, é o fato de procurar tempo, ir até onde se encontrava o paciente e cumprir com os compromissos estabelecidos com a família. Tudo isso eu fazia com agrado, sem me sentir obrigada a fazê-lo e creio que isso é o mais importante ao momento de desempenhar a minha labor"[ E3P3].

"Mesmo depois de acabar o estagio segui fazendo o curativo aproximadamente por seis meses, até que fechou completamente a lesão, sem esperar nada em troca"[E3P3]. 


\section{Discussão}

O conhecimento cientifico evidencia-se através do padrão empírico. Os alunos claramente manifestaram a importância de ter conceitos claros para serem incorporados no momento de fazerem a prática em pacientes com ferimentos crônicos, dessa maneira logram-se integrar os dois componentes (teórico e prático). Igualmente se reconhece e compreende a condição física e emocional (a dor) da pessoa sujeito dos cuidados $(7,23)$. Este padrão possibilita a orientação do cuidado como competência profissional que se faz efetiva através dos conhecimentos adquiridos na formação acadêmica, junto com os estágios formativos (5).

De maneira semelhante, a estética do cuidado se interpreta através da combinação dos sentimentos dos alunos e o seu raciocínio frente ao ato de cuidar. É por isso que os valores e sentimentos estéticos têm apoiado e motivado o encontro do futuro profissional com a piedade, o altruísmo e o profissionalismo científico. Desde esta perspectiva, relaciona-se a arte da enfermagem com o saber que fazer e como estar com a pessoa e a família; é um relacionamento empático onde expressam-se sentimentos e emoções de uma experiência única, que permite que a enfermeira desenvolva maior consciência da realidade subjetiva do cuidado $(23,26)$. No presente estudo, os alunos deixaram sair a sua criatividade e sensibilidade, coincidindo com os resultados de Lavareda \& Contreras que afirmaram que cada momento do cuidado é a oportunidade para se fazer visível a arte particular de cada enfermeiro (a); desse modo, a academia é o espaço próprio para compreender e comunicar o padrão estético $(4,7,27,28)$.

Os presentes resultados coincidem com os de Uribe \& Lagoueyte, para quem a escuta converte-se no momento especial de atenção, marcado pelo respeito e interesse pelos sentimentos que expressa o paciente; assim como falar com a família torna-se num suporte valioso nos momentos difíceis (29).

Por outro lado, a toma de decisões no futuro profissional da área da saúde viu-se refletida através do padrão sociopolítico, através da iniciativa de fazer mais pelo paciente à procura do seu bem estar; estes resultados coincidem com Osorio (9) quem afirmou que deve se incluir a participação da enfermeira quem sabe como e quando agir em relação com o contexto, onde não só se inclui a prática, também os espaços onde se vi- vem experiências de saúde, que são influenciadas por aspectos culturais, históricos, económicos, sociais e políticos. Este padrão requer de habilidades de comunicação e liderança e a certeza que a prática vai além da técnica $(5,9,12)$.

Pode-se destacar, que a atenção da equipe multidisciplinar é um componente de este padrão. A literatura o destaca como um fenómeno do bem estar, onde todos interagem desde um olhar científico com um objetivo comum, como é a atenção do paciente desde uma perspectiva holística, e a sua lesão a tratar como um problema de saúde a ser solucionado (30).

Assim mesmo, o padrão do conhecimento pessoal depende do conhecimento de si mesmo e da subjetividade com a que eu enxergo o outro procurando empatia $(9,24)$. Neste sentido, os futuros profissionais expressaram os seus sentimentos e experimentaram satisfação frente ao ato de cuidar. Este é um dos padrões mais importantes para o direcionamento e o desenvolvimento assertivo do cuidado $(31,32)$.

No relacionado com o padrão ético, que é o componente moral da enfermagem, pode-se dizer que motiva e impulsa as condutas corretas ao atuar, diferenciando-as quando são boas ou não, sempre respeitando a dignidade humana $(9,23,32)$. Os alunos que foram estudados identificaram estes princípios no cuidado da pessoa com lesões crônicas de pele, assim como propunham Bratz \& Sandoval que promovem as competências éticas através do processo de formação $(5,33)$. Desta maneira, na narrativa tiveram-se presentes os valores éticos e princípios de responsabilidade deontológica da enfermagem, como são o respeito, a dignidade humana $\mathrm{e} o$ direito à informação.

No padrão emancipatório, os alunos perceberam a injustiça social que enfrentam os pacientes pelo fato de não terem os materiais necessários aos que tem o direito para continuar com o tratamento das lesões de pele no seu lar, assim mesmo, com autonomia procuraram a maneira de providenciar os recursos necessários para o cuidado. Neste ponto, Ramirez e col sustentam a importância de desenvolver estratégias de acompanhamento para fortalecer este padrão nos futuros profissionais; além disso, afirmam que se requer de professores altamente qualificados para promover a autonomia nos alunoss, de forma que aprendam desde a aula a criar e participar num mundo mais humano e equitativo (34-35). 
ISSN-PRINT

1794-9831

E-ISSN 2322-7028

Vol. 16 No. 3

Sep - Dic 2019

Cúcuta, Colombia
Os presentes resultados são semelhantes aos descritos por Briñez (5), quem formulou propostas claras para o benefício do cuidado da pessoa embora das dificuldades econômicas e geográficas que a maioria das vezes não podem ser modificadas pelo enfermeiro; mas se logra analisar os problemas sociais procurando melhorar e providenciar o cuidado com qualidade.

\section{Conclusões}

- Através do presente estudo, permitiu-se ao aluno desenvolver seu pensamento crítico e reflexivo, projetando o cuidado da pessoa com lesões crônicas de pele desde uma perspectiva de um ser integral, único ao que se satisfazem necessidades.

- O desafio é manter a reflexão sobre os fundamentos epistemológicos da enfermagem, identificando os componentes que direcionam o rumo da formação e a prática dos futuros profissionais de enfermagem.
- O Presente estudo destaca o valor que o aluno outorga aos aspectos humanos que acompanham a adversidade e a criatividade do cuidado, fatores que contribuem ao seu aprendizado de maneira significativa de cada situação cotidiana na prática, sendo o seu paciente inspirador de cuidado.

- Embora que os alunos enfrentaram condições limitantes da abordagem integral das lesões, lograram se virar e fornecer cuidados de qualidade, através dos padrões do conhecimento.

- O uso dos padrões do conhecimento nos atos de cuidado, tem sido pouco explorados desde a disciplina de enfermagem, portanto, este estudo convida a que os enfermeiros os utilizem para fortalecer a sua autonomia e fundamentam a sua identidade profissional.

\section{Conflito de interesses}

Os autores declaram não ter conflito de interesses.

\section{Referencias Bibliográficas}

1. Abril Higuero M. Percepción y experiencia enfermera sobre la atención de la dimensión espiritual de los pacientes en la práctica clínica. [Trabajo de fin de Master] Universidad Internacional de Catalunya; 2013. [consultado 12 diciembre 2017] Disponible en: https://www.recercat.cat/bitstream/ handle/2072/217662/Matea_Abril_Higuero_TFM.pdf?sequence $=1$.

2. Urra Medina E, Hernández Cortina A. La naturaleza del conocimiento de enfermería: Reflexiones para el debate de una mejor comprensión de los cuidados. Rev Cienc. enferm. [Internet]. 2015 [consultado 2 febrero]; 21(3): 113-122. Disponible en: http://dx.doi.org/10.4067/S0717-95532015000300010.

3. Irigibel Uriz X. Los patrones de conocimiento (No) Posibles. Crítica foucaultiana a la clasificación de Barbara Carper. Rev Enfermería en Costa Rica. [Internet]. 2011 [consultado 3 marzo 2018]; 2(1): 30- 36. Disponible en: http://www.binasss.sa.cr/revistas/enfermeria/v32n1/art6.pdf

4. Arias Valencia MM, Gaviria Noreña DL. La investigación cualitativa: un acto creativo por la enfermería. Av.enferm. [Internet]. 2014 [consultado 10 enero 2018]; 32(2):280-291. Disponible en: http:// www.scielo.org.co/pdf/aven/v32n2/v32n2a12.pdf

5. Osorio Murillo O. La investigación en enfermería: un proceso en construcción. Conocimientos en Enfermería [Internet]. 2017 [consultado 18 septiembre 2018]; 1(1):13-23. Disponible en: http://revistasojs.unilibrecali.edu.co/index.php/ce/article/view/399/497

6. Pina Queirós PJ. El conocimiento en enfermería y la naturaleza de sus saberes. Rev. Esc Anna Nery [Internet]. 2016 [consultado el 4 de noviembre de 2017]; 20(3):1-2. Disponible en: http://www.scielo. br/pdf/ean/v20n3/es_1414-8145-ean-20-03-20160079.pdf

7. Baixinho CL, Ferraz I, Carvalho B, Ferreira OM, Ramos R, Helga M. The art and learning patterns of knowing in nursing. Rev. esc. enferm. USP [Internet]. 2014 [consultado 4 mayo 2018]; 48(spe2):164170. Disponible en: http://dx.doi.org/10.1590/S0080-623420140000800024

8. Siles González J. La utilidad práctica de la Epistemología en la clarificación de la pertinencia teórica 
y metodológica en la disciplina enfermera. Rev Index Enferm [Internet]. 2016 [consultado 23 marzo 2018]; 25(1-2):86-92. Disponible en: http://scielo.isciii.es/scielo.php?script=sci_arttext\&pid=S1132$12962016000100020 \& \operatorname{lng}=\mathrm{es}$

9. Osorio Castaño JH. Patrón de conocimiento socio-político en enfermería: reflexiones conceptuales. Revista Cuidarte. [Internet]. 2017 [consultado 4 abril 2018]; 7(2):1352-7. Disponible en: https://www. revistacuidarte.org/index.php/cuidarte/article/view/319/717

10. Muñoz Torres $T$, Casique Casique L. Análisis de la ternura a través de los patrones del conocimiento de Carper: Una experiencia en el cuidado de enfermería. Revista ENE de enfermería [Internet]. 2013 [consultado 5 de mayo 2018]; 7(1). Disponible en: http://ene-enfermeria.org/ojs/index.php/ENE/ar$\underline{\text { ticle/view/254/208 }}$

11. Pech González MI, Casique Cacique L. Experiencia de una relación afectiva en el cuidado de enfermería, con base en los patrones del conocimiento de Bárbara Carper. Rev Ene. [Internet]. 2014 [consultado 3 junio 2018]; 8(3). Disponible en: http://dx.doi.org/10.4321/S1988-348X2014000300010

12. Escobar Castellanos B, Sanhueza Alvarado O. Patrones de conocimiento de Carper y expresión en el cuidado de enfermería: Enfermería. Rev Enfermería Cuidados humanizados [Internet]. 2018 Jun [consultado 17 septiembre 2018]; 7(1):27-42. Disponible en: http://dx.doi.org/10.22235/ech.v7i1.1540

13. Wilches Flórez OC, Wilches Flórez AM. El cuidado, visto por profesionales de la salud, en calidad de familiares de un usuario. Revista Colombiana de Bioética [Internet]. 2016 [consultado 16 enero 2018]; 11(1):23-34. Disponible en: http://www.redalyc.org/articulo.oa? $\mathrm{id}=189246655002$

14. Navarrete Borrero AA. Evidenciando el patrón de conocimiento estético a partir de la narrativa de enfermería. Rev Horiz Enferm. [Internet]. 2013 [consultado 2 febrero 2018]; 24(1): 9-16. Disponible en: http://horizonteenfermeria.uc.cl/images/pdf/24-1/8_editorial_horizonte\%2024-12013.pdf

15. Olivella Fernández MC. El cuidado enfermero a la luz de los patrones de conocimiento. Revista manos al cuidado [Internet]. 2011 [consultado 22 marzo 2018]; 3(3):48-53.Disponible en: http://revistas. ut.edu.co/index.php/manosalcuidado/article/view/1127/880

16. Gómez Rojas ML, Rodríguez Díaz BL. Situación de enfermería como herramienta para enseñar el proceso de atención de enfermería. Revista Cuidarte [Internet]. 2013 [consultado 23 abril 2018]; 4(1). Disponible en: https://doi.org/10.15649/cuidarte.v4i1.16

17. Esperón Güimil JA, Loureiro Rodríguez MT, Antón Fuentes VM., Rosendo Fernández JM, Pérez García I, Soldevilla Agreda JJ. Variabilidad en el abordaje de las heridas crónicas: ¿qué opinan las enfermeras? Rev Gerokomos [Internet]. 2014 [consultado 24 mayo 2018]; 25(4): 171-177. Disponible en: http://scielo.isciii.es/scielo.php?script=sci_arttext\&pid=S1134-928X2014000400007\&lng=es

18. Rumbo Prieto JM. Variabilidad e incertidumbre en el abordaje de las úlceras y heridas crónicas situación actual. Rev Enfermería Dermatológica [Internet]. 2015 [consultado 3 mayo 2018]; 25(9):7-10. Disponible en: https://dialnet.unirioja.es/servlet/articulo? codigo $=5423372$

19. Castro Becerra RA, Rubiano Mesa YL. Experiencia en el cuidado de enfermería: herida de abdomen abierto en el adulto. Revista avances en enfermería. [Internet]. 2011 [consultado 24 abril 2018]; 29(2):319-330. Disponible en www.scielo.org.co/pdf/aven/v29n2/v29n2a11.pdf

20. Restrepo Medrano JC, Tirado Otalvaro AF, Velásquez Vergara SM, Velásquez García KY. Conocimientos relacionados con el manejo de úlceras por presión que tienen los estudiantes de enfermería de una universidad de Medellín, Colombia. Rev Gerokomos [Internet]. 2015 [consultado 1 junio 2018]; 26(2):68-72. Disponible en: http://scielo.isciii.es/scielo.php?script=sci arttext\&pid=S1134928X2015000200007\&lng $=\mathrm{es}$

21. González Consuegra RV, Pérez Valderrama DC, Valbuena Flor LF. Prevención de lesiones de piel: educación en el equipo de salud y familiares de personas hospitalizadas. Revista de la Facultad de Medicina, [Internet]. 2016 [consultado 2 mayo 2018]; 64(2):229-238. Disponible en: https://revistas. unal.edu.co/index.php/revfacmed/article/view/49903/56465 
ISSN-PRINT

$1794-9831$

E-ISSN 2322-7028

Vol. 16 No. 3

Sep - Dic 2019

Cúcuta, Colombia

22. Pererira Frota O, Goulart J, Doas Rolan M, Menis Ferreira A. Impacto de intervencao educativa sobre feridas no cohecimento de técnicos de enfermagem. Rev enfermagem UERJ. [Internet]. 2015 [consultado el 20 mayo 2018]; 23(5):603-9. Disponible en https://www.e-publicacoes.uerj.br/index.php/ enfermagemuerj/article/view/12097

23. Gómez Palencia IP. Técnica de la narrativa en enfermería, patrones de conocimiento y abordaje teórico. Revista ciencias biomédicas [Internet]. 2012 [consultado 11 mayo 2018]; 3(1):174-179.Disponible en: http://www.revista.cartagenamorros.com/pdf/3-1/25ENFERMERIA.pdf

24. Sandoval CA. Investigación Cualitativa. [Internet] California: desarrollo.ut.edu.co, 2002 [consultado 17 enero 2018] Disponible en: http://www.desarrollo.ut.edu.co

25. Prado M, Souza M, Monticelli M, Cometto M, Gómez P. 2013. Investigación Cualitativa en enfermería. Metodología y didáctica. $1^{\mathrm{a}}$ ed. Serie PALTEX, Washington, p. 253.

26. Rodríguez S, Cárdenas M, Pacheco AL, Ramírez M, Ferro N, Alvarado E. Reflexión teórica sobre el arte del cuidado. Enferm. univ [Internet]. 2017 [consultado 16 septiembre 2018]; 14(3): 191-198. Disponible en: http://www.scielo.org.mx/scielo.php?script=sci arttext\&pid=S1665$\underline{70632017000300191 \& \operatorname{lng}=\mathrm{es}}$

27. Contreras Ibacache V. Evidencia del Arte en Enfermería. Rev Enferm. glob. [Internet]. 2013 [consultado 133 abril 2018]; 12(30): 326-331. Disponible en: http://scielo.isciii.es/scielo.php?script=sci arttext\&pid $=$ S1695-61412013000200016\&lng=es

28. Valderrama Sanabria ML, Peña Pita AP, Clavijo Alvarez LM. Narrativa: El estudiante de enfermería aprendiendo el arte de cuidar. Revista Cuidarte [Internet]. 2017 [consultado 12 diciembre 2017]; 8(1):1488-98. Disponible en: https://www.revistacuidarte.org/index.php/cuidarte/article/view/362/773

29. Uribe Velásquez SP, Lagoueyte Gómez MI. "Estar ahí", significado del cuidado espiritual: la mirada de los profesionales de enfermería. Rev av.enferm. [Internet]. 2014 [consultado 3 mayo 2018]; 32(2):261-270. Disponible en: http://www.scielo.org.co/pdf/aven/v32n2/v32n2a10.pdf

30. Esparza Imas G, Fuentes Agúndez A, Morales Pasamar MJ, Nova Rodríguez JM. Visión y experiencia de enfermeras coordinadoras de unidades de heridas crónicas. Rev Gerokomos [Internet]. 2016 [consultado 17 mayo 2018]; 27(3):127-130. Disponible en: http://scielo.isciii.es/scielo.php?script=sci arttext\&pid=S1134-928X2016000300009\&lng=es

31. Rubio Acuña M, Arias Burgos M. Fenomenología y conocimiento disciplinar de enfermería. Rev cubana Enfermer [Internet]. 2013 [consultado 2 mayo 2018]; 29(3):191-198. Disponible en: http://scielo. sld.cu/scielo.php?script $=$ sci_arttext\&pid=S0864-03192013000300005\&lng=es

32. Guerrero Arango M, Loaiza Buitrago D, Muñoz Marín J, Ortiz Mosquera M. Promoción de la Salud: Construcción de Conocimiento Enfermero hacia una Universidad Promotora de la salud y de la vida. Convención Internacional de Salud, CubaSalud [Internet]. 2018 [consultado 18 septiembre 2018]; Disponible en: http://www.convencionsalud2017.sld.cu/index.php/connvencionsalud/2018/paper/ viewFile/2157/751

33. Anna Bratz JK, Sandoval Ramirez M. Ethical competences for the development of nursing care. Rev. Bras. Enferm. [Internet]. 2018 [consultado 17 septiembre 2018]; 71(4):1810-1814. Disponible en: http://www.scielo.br/scielo.php?script=sci arttext\&pid=S0034-71672018001001810\&lng=en

34. Ramírez Elizondo NA, Quintana Zavala MO, Sanhueza Alvarado O, Valenzuela Suazo SV. El paradigma emancipatorio y su influencia sobre el desarrollo del conocimiento en Enfermería. Rev Enferm. glob. [Internet]. 2013 [consultado 8 mayo 2018]; 12(30):410-421. Disponible en: http://scielo.isciii. es/scielo.php?script $=$ sci arttext\&pid $=\mathrm{S} 1695-61412013000200020 \& \operatorname{lng}=\mathrm{es}$

35. Gallardo AI. Evolución del conocimiento en enfermería. Rev Medwave. [Internet]. 2011 [consultado 2 mayo 208]; 11(04). Disponible en https://www.medwave.cl/link.cgi/Medwave/Perspectivas/Opinion/5001 